\title{
What is the role of pulse oximetry in the assessment of patients with community-acquired pneumonia in primary care?
}

\author{
*Thomas Bewicka, Sonia Greenwooda, Wei Shen Lima \\ a Department of Respiratory Medicine, David Evans Building, Nottingham City Hospital, Nottingham, UK
}

Received 29th April 2010; revised version received 13th May 2010; accepted 29th May 2010; online 2nd August 2010

\begin{abstract}
Introduction: Community-acquired pneumonia (CAP) is a common presenting condition in primary care. Assessment of oxygenation status using pulse oximetry is increasingly available, but its precise role in disease severity assessment is unknown.

Aims: To inform the use of pulse oximetry in patients with CAP, including the utility of different oxygenation thresholds, patient subgroups, and interaction with existing severity scores.

Methods: A prospective cohort study of adults with CAP admitted to a UK teaching hospital trust. Oxygen saturations $\left(\mathrm{S}_{\mathrm{p}} \mathrm{O}_{2}\right)$ and the fraction of inspired oxygen were recorded on admission. The value of different $\mathrm{S}_{\mathrm{p}} \mathrm{O}_{2}$ thresholds $(<88 \%, \leq 90 \%, \leq 92 \%$, and $<95 \%)$ in predicting 30-day mortality and critical care admission was analysed.

Results: 467 patients had $\mathrm{S}_{p} \mathrm{O}_{2}$ measured on room air. Admission $\mathrm{S}_{\mathrm{p}} \mathrm{O}_{2} \leq 90 \%$ was observed in $28 \%$ of patients and had reasonable specificity (76\%) for 30-day mortality or critical care admission, but low sensitivity (46\%). Specificity was particularly good for adults $<50$ years of age (90\%) or those with asthma $(92.3 \%)$.

Conclusions: $\mathrm{S}_{\mathrm{p}} \mathrm{O}_{2} \leq 90 \%$ has good specificity but low sensitivity for adverse outcomes in CAP. It complements rather than replaces clinical severity scoring.

(C) 2010 Primary Care Respiratory Society UK. All rights reserved.

T Bewick et al. Prim Care Resp J 2010; 19(4): 378-382

doi:10.4104/pcrj.2010.00049
\end{abstract}

Keywords Pneumonia, pulse oximetry, oxygenation, primary care, severity

See linked editorial by Gupta and Woodhead on pg 301

\section{Introduction}

Community-acquired pneumonia (CAP) is a common condition, with an estimated annual incidence in the UK of 233 per $100,000 .^{1}$ CAP causes over 100,000 admissions annually to hospitals in England and Wales, ${ }^{2}$ and has an estimated mortality of $3 \%$ in patients presenting to primary care and $9-15 \%$ in hospitalised patients. ${ }^{3-5}$ The recommended tool in the UK for CAP severity assessment in primary care is the CRB-65 score. ${ }^{6}$ This wellvalidated score, which stratifies patients for risk of mortality and therefore need for hospital admission, ${ }^{6-9}$ consists of binary variables derived from measures of confusion, respiratory rate, blood pressure and age, but does not include a measure of hypoxaemia.

An assessment of oxygenation is recommended when patients with CAP are admitted to hospital. ${ }^{10}$ The percentage of capillary haemoglobin that is saturated with oxygen $\left(\mathrm{SpO}_{2}\right)$ can be quantified rapidly and non-invasively using a pulse oximeter. Pulse oximeters are increasingly being used in primary care in the assessment of a variety of respiratory conditions, ${ }^{11}$ and national guidelines recommend the use of pulse oximetry in primary care to inform severity assessment and admission decisions. ${ }^{10,12}$ However, few data support these recommendations (grade D evidence).

Arterial hypoxaemia (the partial pressure of oxygen in arterial blood $\left.\left(\mathrm{PaO}_{2}\right)<8 \mathrm{kPa}\right)$ is independently associated with poorer outcomes in hospitalised patients with $\mathrm{CAP}^{13-16}$ and may be useful in identifying patients at higher risk of adverse outcomes despite apparently low severity CAP as measured by current severity scores. ${ }^{17}$ However, arterial blood gas analysis as a measure of hypoxaemia is not routinely available in primary care and is usually inappropriate in patients who do not have low $\mathrm{SpO}_{2}$ or suspected significant metabolic derangement. In contrast, pulse oximetry is

\footnotetext{
* Corresponding author: Dr Thomas Bewick, Department of Respiratory Medicine, Nottingham City Hospital, David Evans Building, Hucknall Road, Nottingham, NG5 1PB, UK. Tel: +44 (0)1159691169 Fax: +44 (0)1159627723 Email: thomasbewick@doctors.org.uk
} 
a rapid and non-invasive investigation. Knowledge of low $\mathrm{SpO}_{2}$ in the emergency department has been shown to alter physician practice significantly, including treatment, investigation and admission decisions, ${ }^{18}$ and delays in oxygen assessment may result in worse patient outcomes. ${ }^{19}$

However, there remains substantial uncertainty regarding the role of pulse oximetry in the context of the CRB-65 score for disease severity assessment in patients presenting to primary care with CAP. In particular, there is uncertainty regarding the thresholds of $\mathrm{SpO}_{2}$ that are associated with clinically significant outcomes. The aims of this study therefore were;

a) to assess the utility of different thresholds of $\mathrm{SpO}_{2}$ in predicting adverse outcomes in CAP

b) to assess the utility of low $\mathrm{S}_{\mathrm{p}} \mathrm{O}_{2}$ as a prognostic tool in subgroups such as the young and those without respiratory comorbidity, and

c) to compare the prognostic value of oxygenation assessment for mortality with existing clinical severity scoring.

The ideal study design to address these questions would be a large cohort study conducted in primary care with follow-through in hospital. A sample size of several thousand would be required to capture enough patients with an adverse outcome (admission to critical care or death) to enable a robust analysis. There are major practical and feasibility hurdles in mounting such a large study. The current study design - which focuses on a cohort of patients hospitalised with CAP - has design limitations but still offers important and useful data that might inform further studies.

\section{Material and methods}

\section{Patient population and recruitment}

Consecutive patients admitted with CAP to a large UK teaching hospital trust between September 2008 and February 2010 were prospectively recruited. Patients were included if they were aged 16 years or more, had at least one acute symptom in keeping with lower respiratory tract infection (breathlessness, cough, sputum or fever), had new infiltrates on a chest radiograph, and were treated by the admitting team for CAP. Patients were excluded if they had been admitted to hospital in the preceding 10 days, had tuberculosis, or had postobstructive pneumonia due to lung cancer. Participants were identified by the investigators on a daily basis from the acute admitting medical wards and enrolled following a diagnostic admission chest radiograph. The route of admission was either referral from primary care or following assessment in the emergency department. All patients were managed in a similar manner according to trust CAP guidelines at the discretion of the attending clinician.

Upon hospital admission, demographic, co-morbidity and severity data were collected for all patients. $\mathrm{S}_{\mathrm{p}} \mathrm{O}_{2}$ levels with the fraction of inspired oxygen $\left(\mathrm{F}_{1} \mathrm{O}_{2}\right)$ as first measured by the triage nurse team were documented. Participants were seen in an outpatient clinic six to eight weeks following discharge to assess clinical and radiological disease resolution. Full ethical approval was gained from the Nottingham Regional Ethics Committee and informed consent was obtained from all patients. "COPD" was defined as any patient with a smoking history more than 20 pack years who had been diagnosed with the condition in primary or secondary care prior to the acute illness.

\section{Statistical considerations}

The primary outcome measure was a combined end point of inpatient mortality within 30 days of admission or admission to a critical care area. Other outcomes examined were length of hospital stay (LOS) and need for mechanical ventilation (MV). Patients were only included in the current study if the initial oxygen assessment was performed on room air.

Data were analysed using SPSS v16.0 (@SPSS inc., 2007). The association of $\mathrm{SpO}_{2}$ with the primary outcome measure was examined with and without adjustment for disease severity using a logistic regression analysis, from which odds ratios were calculated. Groups of patients were further analysed according to admission $\mathrm{SpO}_{2}$ thresholds commonly used in guideline statements ( $<88 \%, \leq 90 \%, \leq 92 \%$, and $<95 \%$ ) using Pearson's $\chi^{2}$ test, and measures of performance including sensitivity and specificity were calculated. Using the most suitable $\mathrm{S}_{\mathrm{p}} \mathrm{O}_{2}$ threshold, patient sub-groups were compared in a similar manner. Continuous variables of other outcomes (such as LOS) were normalised logarithmically prior to analysis using Student's T test. The utility of CRB-65 as a predictor for 30-day mortality was analysed using receiver-operating characteristic (ROC) curves. A binary measure for each of the oxygenation thresholds was added to the individual CRB-65 scores and areas under the curve (AUC) calculated for each ROC curve.

\section{Results}

\section{Patient population}

Of 832 eligible patients enrolled over the period of the study, 365 received pre-admission supplemental oxygen and therefore did not have $\mathrm{S}_{\mathrm{p}} \mathrm{O}_{2}$ levels measured on room air at the time of hospital admission, leaving 467 patients in the study cohort. Mean age was 66.7 years (standard deviation 20.1) and 30-day inpatient mortality was $10.3 \%$. Further demographic and clinical features of the patient cohort are described in Table 1.

Utility of different thresholds of $\mathrm{S}_{\mathrm{p}} \mathrm{O}_{2}$ in predicting adverse outcomes

$\mathrm{S}_{\mathrm{p}} \mathrm{O}_{2}$ measured at the time of admission was found on univariate analysis to be inversely associated with the combined outcome of 30 -day mortality and critical care admission (per unit decrease in $\mathrm{SpO}_{2}$, odds ratio (OR) 1.09, 95\% confidence interval $(\mathrm{Cl})$ 1.05$1.14, \mathrm{p}<0.001)$. This association was maintained after adjustment for disease severity using the CRB-65 score (CRB-65 0 or 1, OR 1.11, 95\% Cl 1.05-1.17, p<0.001; CRB-65 2 and above, OR 1.06, 


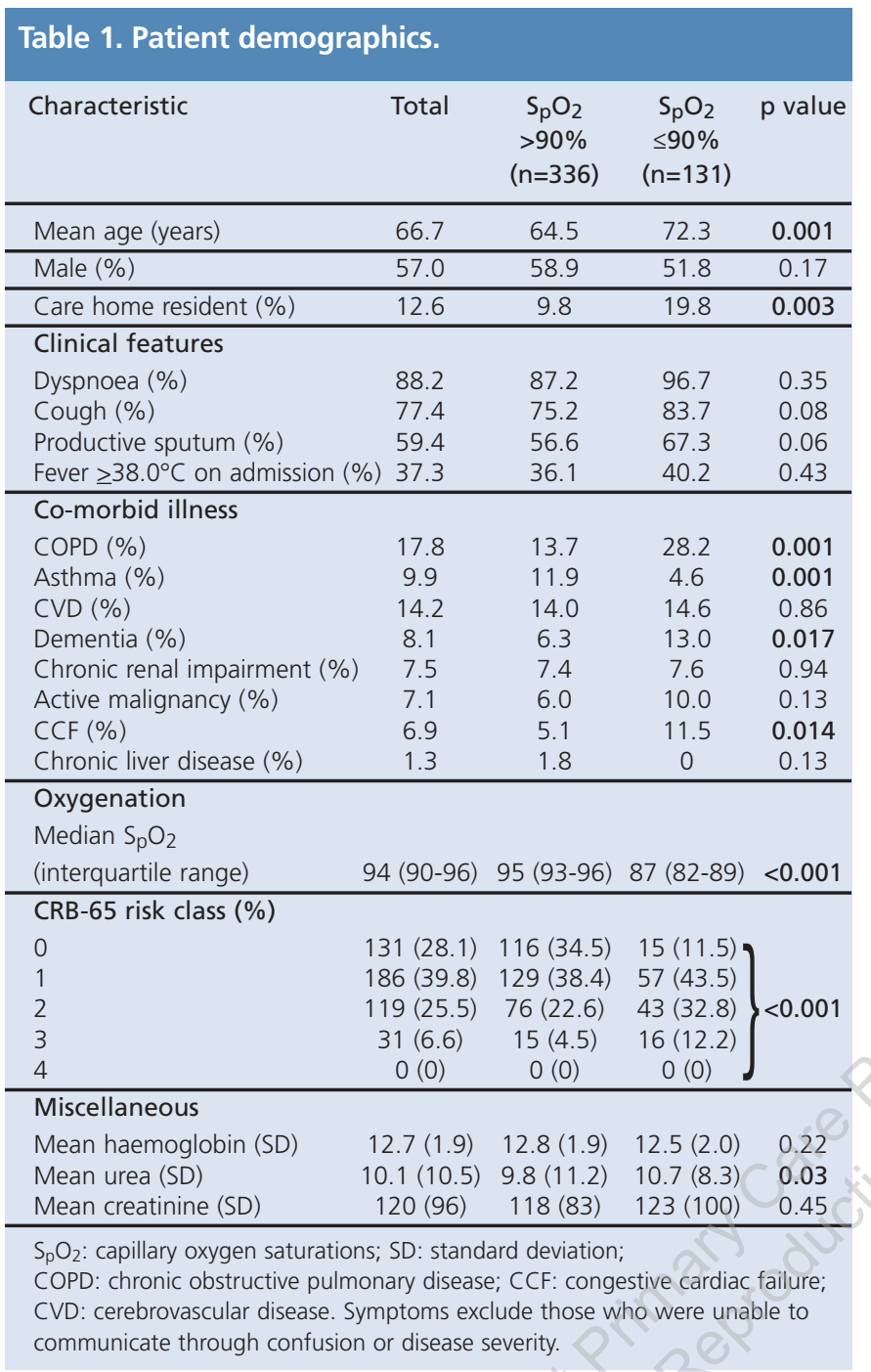

$95 \% \mathrm{Cl} 1.00-1.11, \mathrm{p}=0.04)$. All four commonly used thresholds for hypoxaemia were associated with poorer outcomes (Table 2). There was a statistically significant association between decreasing thresholds of $\mathrm{SpO}_{2}$ and incidence of adverse outcome (for each decrease in threshold, OR 1.42, 95\% Cl 1.22-1.66, $\mathrm{p}<0.001$ ). $\mathrm{SpO}_{2} \leq 90 \%$ was found to have moderate discriminatory value (specificity $>75 \%$ ) while still applying to a reasonable proportion of patients (131/467, 28\%). This threshold was therefore chosen for further analysis.

Utility of $\mathrm{SpO}_{2} \leq 90 \%$ as a prognostic tool in sub-groups The specificity of $\mathrm{SpO}_{2} \leq 90 \%$ as a predictor of mortality or critical care admission was improved when applied to sub-groups of patients, in particular those aged less than 50 years $(90.0 \%)$ and in patients with asthma (92.3\%) (Table 3). $\mathrm{SpO}_{2} \leq 90 \%$ was a less reliable predictor in patients admitted from nursing or residential homes and those with COPD. In patients with $\mathrm{SpO}_{2} \leq 90 \%$, admission to critical care, heed for mechanical ventilation and LOS were each significantly increased (Table 4).

\section{Comparison of the prognostic value of $\mathrm{S}_{\mathrm{p}} \mathrm{O}_{2} \leq 90 \%$ with existing severity scoring}

The area under the curve (AUC) of the receiver-operating characteristic (ROC) curve for CRB-65 in predicting 30-day inpatient mortality in this cohort was 0.768 . When the binary measure of $\mathrm{SpO}_{2} \leq$ or $>90 \%$ was added the AUC was not significantly improved (0.785). For patients with low to moderate severity CAP based on a CRB-65 score of 0 or 1 , $\mathrm{SpO}_{2}$ was $\leq 90 \%$ in $20 / 41$ (48.8\%) of those who subsequently died or were admitted to critical care. The sensitivity of CRB$65 \geq 1$ and $\geq 2$ in predicting 30-day mortality in this cohort was $97.9 \%$ and $70.8 \%$ respectively, but was only $52.1 \%$ for $\mathrm{S}_{\mathrm{p}} \mathrm{O}_{2} \leq 90 \%$.

Table 2. Sensitivities and specificities for 30-day inpatient mortality or critical care admission by thresholds of hypoxaemia.

\begin{tabular}{lcccccccc} 
& Died or CC $(\%)$ & OR & $95 \% \mathrm{Cl}$ & p value & Sensitivity (\%) & Specificity (\%) & PPV (\%) & NPV (\%) \\
\hline $\mathrm{SpO}_{2}<88 \%(\mathrm{n}=69)$ & 36.2 & 3.3 & $1.9-5.7$ & $<0.001$ & 29.8 & 88.5 & 36.2 & 85.2 \\
\hline $\mathrm{SpO}_{2} \leq 90 \%(\mathrm{n}=131)$ & 29.8 & 2.7 & $1.7-4.5$ & $<0.001$ & 46.4 & 76.0 & 29.8 & 86.6 \\
\hline $\mathrm{SpO}_{2} \leq 92 \%(\mathrm{n}=187)$ & 26.7 & 2.6 & $1.6-4.3$ & $<0.001$ & 59.5 & 64.2 & 26.7 & 87.9 \\
\hline $\mathrm{S}_{\mathrm{p}} \mathrm{O}_{2}<95 \%(\mathrm{n}=271)$ & 22.5 & 2.2 & $1.3-3.7$ & 0.003 & 72.6 & 45.2 & 22.5 & 88.3 \\
\hline
\end{tabular}

CC: critical care; OR: odds ratio; Cl: confidence interval; SpO2: percentage of capillary haemoglobin saturated with oxygen; PPV: positive predictive value; NPV: negative predictive value.

Table 3. Value of $\mathrm{SpO}_{2} \leq 90 \%$ in predicting mortality or critical care admission in subgroups of patients with CAP.

\begin{tabular}{lccccc} 
& Died or CC (\%) & Sensitivity (\%) & Specificity (\%) & PPV (\%) & NPV (\%) \\
\hline All $(n=467)$ & 18.0 & 46.4 & 76.0 & 29.8 & 86.6 \\
\hline Age $<65(n=179)$ & 14.5 & 50.0 & 87.6 & 38.5 & 91.2 \\
\hline Age $<50(n=92)$ & 13.0 & 41.7 & 90.0 & 38.5 & 91.1 \\
\hline Age $<65$ and no COPD $(n=161)$ & 13.7 & 40.9 & 87.9 & 34.6 & 21.6 \\
\hline COPD $(n=83)$ & 18.1 & 53.3 & 57.4 & 50.0 & 84.8 \\
\hline Asthmatic $(n=46)$ & 15.2 & 42.9 & 92.3 & 34.8 & 90.0 \\
\hline Care home resident $(n=59)$ & 27.1 & 56.3 & 60.5 & & 78.8 \\
\hline CC: critical care; PPV: positive predictive value; NPV: negative predictive value; COPD: chronic obstructive pulmonary disease. &
\end{tabular}




\begin{tabular}{|c|c|c|c|}
\hline & $\begin{array}{c}\mathrm{S}_{\mathrm{p}} \mathrm{O}_{2}>90 \% \\
(\mathrm{n}=336)\end{array}$ & $\begin{array}{c}\mathrm{S}_{\mathrm{p}} \mathrm{O}_{2} \leq 90 \% \\
(\mathrm{n}=131)\end{array}$ & $p$ value \\
\hline Inpatient death by 30 days (\%) & 6.8 & 19.1 & $<0.001$ \\
\hline Critical care admission (\%) & 7.4 & 15.3 & 0.01 \\
\hline $\mathrm{MV}(\%)$ & 1.8 & 5.3 & 0.04 \\
\hline Median LOS in days (IQR) & $6.56(8.54)$ & $9.75(10.33)$ & $<0.001$ \\
\hline
\end{tabular}

\section{Discussion}

This study explored the utility of pulse oximetry in predicting outcome for patients admitted to hospital with CAP. Increasing levels of hypoxaemia were found to be significantly associated with higher odds of either 30-day mortality or critical care admission, even after adjustment for disease severity using the CRB-65 score. This is consistent with findings from a US CAP cohort that also demonstrated an association between low $\mathrm{SpO}_{2}$ levels measured on admission and a higher 30-day mortality and incidence of admission to critical care. ${ }^{20}$ Compared to other threshold levels of hypoxaemia, $\mathrm{SpO}_{2} \leq 90 \%$ was found in a significant proportion of patients admitted with CAP (28\%) whilst retaining a reasonably good specificity (76\%) for 30-day mortality or critical care admission. The specificity for adverse outcomes was particularly good when applied to patients with asthma (92\%) and those who were $<50$ years old $(90 \%)$.

\section{Proposed practical use of pulse oximeters}

Measures of $\mathrm{SpO}_{2}$ are increasingly being utilised by general practitioners as the "fifth vital sign". ${ }^{21}$ Various possible interpretations of this sign are that "high" $\mathrm{S}_{p} \mathrm{O}_{2}$ levels might be reassuring in a patient who would otherwise cause clinical concern, or that "low" $\mathrm{S}_{\mathrm{p}} \mathrm{O}_{2}$ levels predict higher severity and therefore need for admission to hospital. The results from this study suggest that a threshold of $\mathrm{SpO}_{2} \leq 90 \%$ may be used to "rule in" high severity CAP, even in patients that do not meet the high severity criteria of clinical scores such as CRB-65. This would apply especially to younger patients, those with asthma, or those without pre-existing significant lung disease. However, the poor sensitivity of hypoxaemia in the identification of patients at risk of adverse outcomes means that pulse oximetry cannot be relied upon as the sole means of severity assessment in CAP. In particular, it means that it is not possible to "rule out" an adverse outcome in a normoxaemic patient with CAP. Instead, clinical severity scores such as CRB-65 should remain the primary method for severity assessment of CAP in primary care, with pulse oximetry used as a secondary measure to inform clinical judgment in those patients who are of clinical concern in the face of a CRB-65 score of 0 or 1.

\section{Mechanism of the association of hypoxaemia with adverse outcomes}

These data suggest that hypoxaemia should be considered separately to variables such as blood pressure, mental confusion and respiratory rate which are incorporated into the CRB-65 score. The latter variables are closely linked to systemic disease and sepsis (and therefore mortality) whereas hypoxaemia is a disease- and organ-specific measure, primarily of the level of shunt within the lungs. Physiological variables such as pulse, blood pressure and respiratory rate are unaffected by substantial hypoxaemia in healthy volunteers, ${ }^{22}$ and correction of hypoxaemia has no influence on outcome either in a postoperative setting ${ }^{23}$ or in moderately hypoxaemic patients with CAP treated with continuous positive airways pressure (CPAP). ${ }^{24}$ This may reflect the oxygen dissociation curve, which suggests that oxygen delivery to the tissues is only compromised at levels of $\mathrm{S}_{\mathrm{p}} \mathrm{O}_{2}$ that are far lower than those associated with hypoxaemia as recognised within current practice. Therefore it may not be hypoxaemia per se that contributes to the adverse outcome, but that low $\mathrm{SpO}_{2}$ levels allow identification of the subgroup of patients who have severe single organ disease that falls short of influencing the sepsis-driven variables identified by most current severity scores. In patients with chronic respiratory disease such as COPD, there is significant pre-existing ventilation/ perfusion mismatch which means that hypoxaemia is a feature of "normal" physiology. Thus in these patients, a low $\mathrm{SpO}_{2}$ is not necessarily an acute pathological feature (in contrast to confusion, high respiratory rates or hypotension), and might explain why hypoxaemia was found to be less discriminatory for clinical outcomes.

\section{Study limitations}

This study was performed in an exclusively hospitalised cohort of patients and therefore raises questions regarding the applicability of these data to a primary care population. However, only patients whose admission $\mathrm{SpO}_{2}$ values were recorded on room air were studied and it is likely that these values would have been similar to values that might have been obtained in a primary care environment. In addition, a wide range in $\mathrm{SpO}_{2}$ levels, disease severity and clinical outcomes were represented in the study cohort. These features further increase the potential generalisability of the results. We are unable to comment on those patients with CAP who were not admitted to hospital, and a further study involving such patients is warranted. This study also allows no comment to be made concerning the value of pulse oximetry in discriminating pneumonic from non-pneumonic lower respiratory tract infection. A separate study in a cohort with suspected CAP, which will potentially include patients with nonpneumonic lower respiratory tract infection as well as other diagnoses, is also of great interest and would be important to enable the results of the current study to be applied more widely.

\section{Conclusion}

$\mathrm{SpO}_{2} \leq 90 \%$ has good specificity but low sensitivity for adverse outcomes in CAP, and therefore complements rather 
Difficulties encountered during this study:

- Applicability of a hospitalised cohort to a primary care setting.

- Use of chest radiography as an inclusion criterion maintains diagnostic certainty, but in the majority of cases general practitioners rely on a clinical rather than radiological diagnosis of CAP.

\section{Alternative methodologies:}

- A cohort study of all lower respiratory tract infection presenting to primary care.

\section{New questions arising from the study:}

- What is the utility of pulse oximetry in patients with non-pneumonic lower respiratory tract infection?

Lessons for clinical practice:

- Oxygenation assessment complements but does not replace severity scoring with CRB-65.

than replaces clinical severity scoring tools. It is particularly useful in patients with asthma or younger patients who do not have chronic respiratory disease.

\section{Conflict of interest}

None declared.

\section{References}

1. Myles PR, McKeever TM, Pogson Z, Smith CJP, Hubbard RB. The incidence of pneumonia using data from a computerized general practice database. Epidemiol Infect 2009;137(5):709-16. http://dx.doi.org/10.1017/ S0950268808001428.

2. Trotter CL, Stuart JM, George R, Miller E. Increasing hospital admissions for pneumonia, England. Emerg Infect Dis 2008;14(5):727-33. http://dx.doi.org/ 10.3201/eid1405.071011

3. Woodhead MA, Macfarlane JT, McCracken JS, Rose DH, Finch RG. Prospective study of the aetiology and outcome of pneumonia in the community. Lancet 1987;1(8534):671-4. http://dx.doi.org/10.1016/50140-6736(87)90430-2

4. Lim WS, Macfarlane JT, Boswell TC, et al. Study of community acquired pneumonia aetiology (SCAPA) in adults admitted to hospital: implications for management guidelines. Thorax 2001;56(4):296-301. http://dx.doi.org/10.1136/thorax.56.4.296

5. Chalmers JD, Singanayagam A, Hill AT. C-reactive protein is an independent predictor of severity in community-acquired pneumonia. Am J Med 2008;121(3):219-25. http://dx.doi.org/10.1016/j.amjmed.2007.10.033.

6. Lim WS, van der Eerden MM, Laing R, et al. Defining community acquired pneumonia severity on presentation to hospital: an international derivation and validation study. Thorax 2003;58(5):377-82. http://dx.doi.org/10.1136/ thorax.58.5.377

7. Ewig S, Birkner N, Strauss R, et al. New perspectives on community-acquired pneumonia in 388406 patients. Results from a nationwide mandatory performance measurement programme in healthcare quality. Thorax 2009;64(12):1062-9. http://dx.doi.org/10.1136/thx.2008.109785.

8. Man SY, Lee N, Ip M, et al. Prospective comparison of three predictive rules for assessing severity of community-acquired pneumonia in Hong Kong. Thorax
2007;62(4):348-53. http://dx.doi.org/10.1136/thx.2006.069740.

9. Bauer T, Ewig S, Marre R, Suttorp N, Welte T, Group CAPNETZS. CRB-65 predicts death from community-acquired pneumonia. J Intern Med 2006;260(1):93-101. http://dx.doi.org/10.1111/j.1365-2796.2006.01657.x

10. Lim WS, Baudouin SV, George RC, et al. BTS guidelines for the management of community acquired pneumonia in adults: update 2009. Thorax 2009;64 Suppl 3:iii1-ii55. http://dx.doi.org/10.1136/thx.2009.121434.

11. Potter VAJ. Pulse oximetry in general practice: how would a pulse oximeter influence patient management? Eur J Gen Pract 2007;13(4):216-20. http://dx.doi.org/10.1080/13814780701574762.

12. Levy ML, Jeune IL, Woodhead MA, Macfarlaned JT, Lim WS, on behalf of the British Thoracic Society Community Acquired Pneumonia in Adults Guideline Group. Primary care summary of the British Thoracic Society Guidelines for the management of community acquired pneumonia in adults: 2009 update. Endorsed by the Royal College of General Practitioners and the Primary Care Respiratory Society UK. Prim Care Resp J 2010;19(1):21-7. http://dx.doi.org/ 10.4104/pcrj.2010.00014

13. Rosón B, Carratalà J, Dorca J, Casanova A, Manresa F, Gudiol F. Etiology, reasons for hospitalization, risk classes, and outcomes of community-acquired pneumonia in patients hospitalized on the basis of conventional admission criteria. Clin Infect Dis 2001;33(2):158-65. http://dx.doi.org/10.1086/321808.

14. Mortensen EM, Coley CM, Singer DE, et al. Causes of death for patients with community-acquired pneumonia: results from the Pneumonia Patient Outcomes Research Team cohort study. Arch Intern Med 2002;162(9):1059-64. http://dx.doi.org/10.1001/archinte.162.9.1059

15. España PP, Capelastegui A, Gorordo I, et al. Development and validation of a clinical prediction rule for severe community-acquired pneumonia. Am J Respir Crit Care Med 2006;174(11):1249-56. http://dx.doi.org/10.1164/rccm.200602-1770C.

16. Wu CL, Lin FJ, Lee SY, et al. Early evolution of arterial oxygenation in severe community-acquired pneumonia: a prospective observational study. J Crit Care 2007;22(2):129-36. http://dx.doi.org/10.1016/j.jcrc.2006.06.009.

17. Sanz F, Restrepo MI, Fernández E, et al. Is it possible to predict which patients with mild pneumonias will develop hypoxemia? Respir Med 2009;103(12):1871-7. http://dx.doi.org/10.1016/j.rmed.2009.06.013.

18. Mower WR, Sachs C, Nicklin EL, Safa P, Baraff $\sqcup$. Effect of routine emergency department triage pulse oximetry screening on medical management. Chest 1995;108(5):1297-1302. http://dx.doi.org/10.1378/chest.108.5.1297

19. Blot SI, Rodriguez A, Solé-Violán J, et al. Effects of delayed oxygenation assessment on time to antibiotic delivery and mortality in patients with severe communityacquired pneumonia. Crit Care Med 2007;35(11):2509-14. http://dx.doi.org/ 10.1097/01.CCM.0000287587.43801.9C

20. Levin KP, Hanusa BH, Rotondi A, et al. Arterial blood gas and pulse oximetry in initial management of patients with community-acquired pneumonia. J Gen Intern Med 2001;16(9):590-8. http://dx.doi.org/10.1046/j.1525-1497.2001.016009590.x

21. Neff TA. Routine oximetry. A fifth vital sign? Chest 1988;94(2):227 http://dx.doi.org/10.1378/chest.94.2.227a

22. Thrush DN, Downs JB, Hodges M, Smith RA. Does significant arterial hypoxemia alter vital signs? J Clin Anesth 1997;9(5):355-7. http://dx.doi.org/10.1016/S09528180(97)00061-5

23. Pedersen T, Pedersen BD, Møller AM. Pulse oximetry for perioperative monitoring. Cochrane Database Syst Rev. 2003;(3):CD002013. http://dx.doi.org/10.1002/ 14651858.CD002013.

24. Delclaux C, L'Her E, Alberti C, et al. Treatment of acute hypoxemic nonhypercapnic respiratory insufficiency with continuous positive airway pressure delivered by a face mask: A randomized controlled trial. JAMA 2000;284(18):2352-60.

\section{Available online at http://www.thepcrj.org}

